\title{
LES/RANS Simulation of a Supersonic Reacting Wall Jet
}

\author{
Jack R. Edwards*, John A. Boles ${ }^{\dagger}$ \\ North Carolina State University, Raleigh, NC \\ Robert A. Baurle f $^{\ddagger}$ \\ NASA Langley Research Center, Hampton, VA
}

\begin{abstract}
This work presents results from large-eddy / Reynolds-averaged Navier-Stokes (LES/RANS) simulations of the well-known Burrows-Kurkov supersonic reacting wall-jet experiment. Generally good agreement with experimental mole fraction, stagnation temperature, and Pitot pressure profiles is obtained for non-reactive mixing of the hydrogen jet with a non-vitiated air stream. A lifted flame, stabilized between 10 and $22 \mathrm{~cm}$ downstream of the hydrogen jet, is formed for hydrogen injected into a vitiated air stream. Flame stabilization occurs closer to the hydrogen injection location when a threedimensional combustor geometry (with boundary layer development resolved on all walls) is considered. Volumetric expansion of the reactive shear layer is accompanied by the formation of large eddies which interact strongly with the reaction zone. Time averaged predictions of the reaction zone structure show an under-prediction of the peak water concentration and stagnation temperature, relative to experimental data and to results from a Reynolds-averaged Navier-Stokes calculation. If the experimental data can be considered as being accurate, this result indicates that the present LES/RANS method does not correctly capture the cascade of turbulence scales that should be resolvable on the present mesh. Instead, energy is concentrated in the very largest scales, which provide an overmixing effect that excessively cools and strains the flame. Predictions improve with the use of a low-dissipation version of the baseline piecewise parabolic advection scheme, which captures the formation of smaller-scale structures superimposed on larger structures of the order of the shear-layer width.
\end{abstract}

ombustion processes occurring in high-speed propulsion devices can be strongly impacted by finite-rate chemistry and turbulence / chemistry interactions, as well as large-scale unsteady behavior caused by intermittent ignition events, shock / boundary layer interactions, and vortex dynamics. The state of the practice in high-speed engine component simulations [1] solves the Reynolds-Averaged Navier-Stokes (RANS) equations, expanded to include separate equations for species transport. Closure is usually accomplished through two-equation turbulence models in conjunction with Boussinesq and gradient-diffusion assumptions. Chemical reaction source terms are usually formulated using the law of mass action, and the effects of turbulence fluctuations on reaction rates are either completely ignored or modeled via eddy break up and/or assumed PDF methods. This standard model been used successfully in the design of scramjet-powered vehicles such as NASA's Hyper-X, the University of Queensland's HyShot program, and the U.S. Air Force's Scramjet Engine Demonstrator, but the ability of the model to handle highly transient physics of the types mentioned above is questionable at best.

Recent work [2-5] has focused on the development of a class of hybrid large-eddy simulation / Reynoldsaveraged Navier Stokes (LES/RANS) strategies specially designed for strongly-interacting, wall-bounded flows characteristic of high-speed propulsion devices. Applications to this point have focused on boundary layer physics, shock / boundary layer interactions, and fuel injection and mixing without combustion. In this paper, we begin to evaluate these procedures for supersonic combusting flows. Some prior work in applying large-eddy simulation methods to supersonic combustion problems has been reported in Genin, et al. [6,7] and Berglund and Fureby [8], who simulated hydrogen-air combustion behind a wedge-shaped flameholder using linear-eddy and flamelet-type

\footnotetext{
${ }^{*}$ Professor, Department of Mechanical and Aerospace Engineering, Associate Fellow, AIAA.

${ }^{\dagger}$ Research Assistant, currently Staff Scientist, Taitech, Inc., Beavercreek, OH, Member, AIAA

₹ Aerospace Engineer, Hypersonic Air Breathing Propulsion Branch, Associate Fellow, AIAA
} 
subgrid combustion models. In general, reasonable agreement with experimental temperature and velocity profiles [9] was obtained, but the results were no better than those obtained using a flamelet-type RANS closure by Oevermann, et al. [10]. In a later study, Berglund, et al. [11] considered a range of turbulent combustion models and subgrid closures in their simulations of supersonic combustion in a configuration studied at ONERA/JAXA. They found better agreement with experimental OH-PLIF images when a seven-step finite rate chemistry mechanism was employed, but the effects of the various subgrid closures considered were inconclusive. Peterson and Candler $[12,13]$ describe the application of a detached-eddy simulation method to the SCHOLAR supersonic-combustion experiment [14]. Reasonable agreement with wall pressure distributions and experimental CARS images is reported, but a lack of centerplane symmetry is also displayed in the time-averaged results.

In this work, we focus on the Burrows-Kurkov reacting wall jet experiment [15,16], which is a well-known test case for supersonic combustion models.[17-21] In the experiment, vitiated air is passed through a Mach 2.5 nozzle into a stepped-wall combustor, where it mixes with sonic hydrogen injected through a vertical slot. (Figure 1) The experiments provide data for inert gas mixing (in which nitrogen gas is used to replace oxygen in the air stream) and mixing followed by combustion (with oxygen present in the air stream). The Burrows-Kurkov database is extensive, including surveys of pitot pressure and stagnation temperature, gas-sampling mole fraction measurements, ignition onset locations (obtained from visual imaging), and wall pressure measurements. Our motivation in considering this older database is two-fold. First, accurate predictions of the time-averaged reactive scalar profiles (obtained experimentally through gas-sampling) can be achieved using 2D RANS models.[17-21] In some cases, this is through a trial and error procedure, as the predicted location of the flame is sensitive to the assumed state of the incoming boundary layer, the choice of hydrogen-air oxidation mechanism, and the type of turbulence closure involved. It is an open question whether a more 'high fidelity' method, such as LES or LES/RANS, can provide equivalent or better predictions. Secondly, the fact that accurate RANS predictions have been obtained assuming 2D flow gives rise to the possibility that LES/RANS calculations may be performed on a domain with periodic boundary conditions imposed in the spanwise direction. As shown later, this assumption might not be entirely justified. The major problem with the Burrows - Kurkov database is that the boundary conditions cannot be specified precisely, as the geometry of the wind tunnel that provides the vitiated air to the combustor section is not given in the reports. One must idealize the inflow in some fashion, and there is not enough data to assess some factors, such as the growth rate of boundary layers on the sides of the combustor.

This paper describes results from RANS and LES/RANS simulations of the Burrows and Kurkov supersonic combustion experiment, obtained on domains with periodic boundary conditions imposed and on fully 3D domains that also capture the time-dependent growth of boundary layers on the top and side walls of the combustor.

\section{Numerical Formulation}

\section{A. Thermodynamic Model}

The computational model used in this investigation solves the Navier-Stokes equations governing a mixture of thermally-perfect gases. A seven-species gas model for hydrogen oxidation [22,23] is used. Thermodynamic curve fits from McBride, et al. [24] are used for species specific heats and enthalpies. Wilke's law is used for the mixture viscosity, and the mixture thermal conductivity is obtained from the assumption of a constant Prandtl number (0.72). Molecular diffusion processes are described using Fick's law, parameterized by a constant Schmidt number of 0.5. The law of mass action is used to formulate source terms describing production / depletion of chemical species.

\section{B. Turbulence Model}

The turbulence model used in this work is a hybrid large-eddy simulation / Reynolds-averaged Navier-Stokes (LES/RANS) technique first presented in [2] and evaluated for several high-speed wall-bounded flows in [3-5]. In this strategy, the RANS model (Menter's k- $\omega$ [25]) is used as a near-wall closure within an overall large-eddy simulation framework. A model constant that controls the location of the RANS-to-LES region within a boundary layer is calculated to be 22.17 using procedures described in [2] and [3]. Conditions within the Burrows / Kurkov combustor are such that the LES model is used for $~ 95 \%$ of the flow. The subgrid model used for the LES is an algebraic form from Lenormand, et al. [26]:

$$
v_{t, M}=C_{M} S^{1 / 2}\left(q^{2}\right)^{1 / 4} \Delta^{3 / 2}, C_{M}=0.06
$$

with 


$$
S=\left[\frac{\partial \tilde{u}_{i}}{\partial x_{j}} \frac{\partial \tilde{u}_{j}}{\partial x_{i}}+\frac{\partial \tilde{u}_{i}}{\partial x_{j}} \frac{\partial \tilde{u}_{i}}{\partial x_{j}}-\frac{2}{3}\left(\frac{\partial \tilde{u}_{i}}{\partial x_{i}}\right)^{2}\right]^{1 / 2}
$$

An estimate of the subgrid kinetic energy is obtained by test-filtering the resolved-scale velocity data:

$$
q^{2}=\frac{1}{2}\left(\tilde{u}_{k}-\hat{\tilde{u}}_{k}\right)^{2}
$$

Closures for turbulent heat-flux and diffusion terms are standard gradient-diffusion formulations, parameterized respectively by constant values of the turbulent Prandtl number (0.9) and the turbulent Schmidt number (0.5).

The inflow boundary layer for the LES/RANS simulations is sustained through a recycling / rescaling technique, applied to the fluctuating fields.[2,3] For the calculations performed in the complete 3D combustor, periodic flow cannot be assumed, and a more general recycling / rescaling procedure [27], valid for flows affected by multiple walls, is used. As of this writing, the chemical source terms are evaluated using filtered mean values. Solutions are also obtained using the parent RANS model for purposes of comparison.

\section{Numerical Discretization}

The Navier-Stokes equations are formulated in a cell-centered finite-volume manner and are solved on a simplyconnected multi-block mesh. Inviscid fluxes are discretized using variants of the piecewise parabolic method (PPM, [28]) along with Edwards' low diffusion flux splitting scheme [29]. The primitive-variable vector $V=\left[p_{s}, u, v, w, T, k, \omega\right]^{T}$ is used in the reconstruction. If left- and right-state information based on simple averages is provided to LDFSS, the interface flux that results should be kinetic-energy-conserving in the sense of Jameson [30] and Subbareddy and Candler [31]. The initial step in the PPM reconstruction sets left-and right states to

$$
V_{L, i+1 / 2}^{A}=V_{R, i+1 / 2}^{A}=\frac{7}{12}\left(V_{i}+V_{i+1}\right)-\frac{1}{12}\left(V_{i+2}-V_{i-1}\right)
$$

which yields a fourth-order central difference approximation on uniform meshes. Monotonicity preservation is enforced by a cell-by-cell resetting of left and right states in accord with the following algorithm:

$$
\begin{aligned}
& V_{L, i+1 / 2}^{M}=V_{L, i+1 / 2}^{A} \\
& V_{R, i-1 / 2}^{M}=V_{R, i-1 / 2}^{A} \\
& \text { if } \operatorname{sgn}\left[\left(V_{L, i+1 / 2}^{A}-V_{i}\right)\left(V_{i}-V_{R, i-1 / 2}^{A}\right)\right]=-1 \text {, then } \\
& \quad V_{L, i+1 / 2}^{M}=V_{R, i-1 / 2}^{M}=V_{i} \\
& \text { else } \\
& \qquad C=V_{L, i+1 / 2}^{A}-V_{R, i-1 / 2}^{A} ; \quad D=6\left[V_{i}-\frac{1}{2}\left(V_{L, i+1 / 2}^{A}+V_{R, i-1 / 2}^{A}\right)\right] \\
& \text { if }(D \times C>C \times C) \text { then } V_{R, i-1 / 2}^{M}=3 V_{i}-2 V_{L, i+1 / 2}^{A} \\
& \quad \text { elseif }(-C \times C>D \times C) \text { then } V_{L, i+1 / 2}^{M}=3 V_{i}-2 V_{R, i-1 / 2}^{A} \\
& \text { end if } \\
& \text { end if }
\end{aligned}
$$

leading to final left- and right-state values (superscript ' $M$ ') that are different from the averaged ones (superscript 'A'). The amount of numerical dissipation added at a cell interface is proportional to the difference in left- and right-state values. While enforcing monotonicity preservation helps in shock-capturing, it compromises the ability of the scheme to resolve small-scale turbulent structures. One means of alleviating this problem is to blend the averaged values (Eq. 4) with the monotonicity-preserving values (Eq. 5) so that the former is used in regions of high vorticity (boundary layers, shear layers) and the latter is used in more 'inviscid' regions, where strong shocks might be present. Subbareddy and Candler [31] utilize a function due to Ducros, et al. [32], defined at a mesh cell,

$$
f=\frac{(\nabla \cdot \vec{V})^{2}}{(\nabla \cdot \vec{V})^{2}+|\omega|^{2}+\varepsilon^{2}}, \quad \varepsilon=1 \times 10^{-8} V_{\infty} / \max (\overline{\Delta x}, \overline{\Delta y}, \overline{\Delta z}),
$$

to perform similar switch in their flux-reconstruction scheme. Here, the divergence of velocity is compared with the vorticity value. If the latter is much larger (in shear and boundary layers, for example), the function moves toward zero, and in free-stream regions near shocks, the function approaches one. At a particular cell interface i+1/2, we use the function as follows: 


$$
\begin{aligned}
& V_{L, i+1 / 2}=V_{L, i+1 / 2}^{A}+\max \left(f_{i}, f_{i+1}, 0.1\right)\left(V_{L, i+1 / 2}^{M}-V_{L, i+1 / 2}^{A}\right) \\
& V_{R, i+1 / 2}=V_{R, i+1 / 2}^{A}+\max \left(f_{i}, f_{i+1}, 0.1\right)\left(V_{R, i+1 / 2}^{M}-V_{R, i+1 / 2}^{A}\right)
\end{aligned}
$$

In the results that follow, this scheme is referred to as LD-PPM, for low-dissipation PPM. Viscous and diffusive terms appearing in the equation system are discretized using second-order central differences.

\section{Time Advancement}

Time integration is facilitated by a planar relaxation sub-iteration procedure based on a Crank-Nicholson - type discretization of the unsteady equations. The specific form used is

$$
\Omega \frac{U^{n+1, k}-U^{n}}{\Delta t}+\frac{1}{2}(1+\theta) R\left(V^{n+1, k}\right)+\frac{1}{2}(1-\theta) R\left(V^{n}\right)=0
$$

where $\Omega$ is the cell volume, $\Delta t$ is the time step (set to $1 \mathrm{e}-7 \mathrm{~s}$ for all cases presented), $U$ is the vector of conserved variables, and $R$ is the residual vector. The function $\theta$ is defined as

$$
\theta=\frac{1}{2}\left(1-\tanh \left(\frac{d-d_{t}}{\Delta d}\right)\right), \quad d_{t}=1 \times 10^{-4} \mathrm{~m}, \Delta d=0.2 d_{t}
$$

Here, $d$ is the distance to the nearest solid surface. The present algorithm is susceptible to grid-scale noise in the pressure and transverse-velocity fields at mesh cells with high aspect ratio, independent of whether or not the lowdissipation PPM is used. The function $\theta$ switches the time discretization from Crank-Nicholson to Euler implicit for mesh cells essentially within the laminar sub-layer. Some loss of temporal accuracy results, but the alternative is either poor convergence of the sub-iterations or solution divergence if the oscillations grow large enough. The code is parallelized using domain-decomposition / MPI message-passing methods. Jacobian matrix elements are stored over the number of blocks mapped to a particular processor, allowing the "freezing" of the matrix elements and their factorization over the duration of the sub-iterations. This reduces the computational workload significantly.

\section{E. Computational Grids, Initial Conditions, and Boundary Conditions}

Two meshes are used for the calculations that assume spanwise periodicity. The first mesh contains 7938720 cells, distributed over 120 blocks. This mesh extends $+/-2.55 \mathrm{~cm}$ (the width of the combustor) in the spanwise direction. The second mesh contains 11643456 cells and extends $+/-3.74 \mathrm{~cm}$ in the spanwise direction. The calculations that account also for boundary layer development on the sidewalls utilize a mesh that also contains 11643456 cells. This mesh is clustered to the sidewalls while maintaining the same mesh spacing near the X-Y centerplane as the other meshes. The minimum cell spacing at all solid surfaces is $0.005 \mathrm{~mm}$. In the absence of details of the wind-tunnel geometry, a simulation of flow over a $1 \mathrm{~m}$ flat plate is used to generate an initial boundary layer of about $1 \mathrm{~cm}$ thick at the entrance of the combustor. The nominal flow conditions as applied at the beginning of the flat plate and within the hydrogen jet nozzle are listed in Table 1.

Table 1: Reference Conditions for Burrows / Kurkov Experiments

\begin{tabular}{|l|l|l|}
\hline property & inert gas & vitiated air \\
\hline $\mathrm{U}_{\infty}(\mathrm{m} / \mathrm{s})$ & 1781.0 & 1741.4 \\
\hline $\mathrm{T}_{\infty}(\mathrm{K})$ & 1130.0 & 1237.9 \\
\hline $\mathrm{P}_{\infty}(\mathrm{Pa})$ & 96000.0 & 96000.0 \\
\hline $\mathrm{Y}_{\mathrm{N} 2}$ & 0.7324 & 0.486 \\
\hline $\mathrm{Y}_{\mathrm{O} 2}$ & 0.0509 & 0.258 \\
\hline $\mathrm{Y}_{\mathrm{H} 2}$ & 0.0005 & 0.000 \\
\hline $\mathrm{Y}_{\mathrm{H} 2 \mathrm{O}}$ & 0.2162 & 0.256 \\
\hline $\mathrm{To}_{\mathrm{H} 2}(\mathrm{~K})$ & 314.0 & 314.0 \\
\hline $\mathrm{Po}_{\mathrm{H} 2}(\mathrm{~Pa})$ & 216675.0 & 216675.0 \\
\hline
\end{tabular}

To initialize the LES/RANS solutions, two- and three-dimensional RANS solutions are first computed over a region of the combustor extending from $-0.1724 \mathrm{~m}$ upstream of the vertical hydrogen injection slot to $0.4 \mathrm{~m}$ downstream of the slot. .

The time for data collection after the tunnel starts is listed as being 2.5 seconds, so there is not enough time for the walls to reach a steady-state or adiabatic condition. A procedure that uses the time constant of the material to estimate a penetration depth of the heating load is thus employed.[33] The time constant is defined as 


$$
t_{c}=\frac{d_{p}^{2} \rho_{s} C_{p, s}}{k_{s}},
$$

and given an estimated exposure time of $2.5 \mathrm{~s}$ and values for density, specific heat, and thermal conductivity of copper, the depth of penetration can be estimated as being $d_{p}=0.017 \mathrm{~m}$. The boundary condition applied along the combustor surfaces matches the heat flux from the fluid to the surface with that from the surface to a fictitious cell location $0.017 \mathrm{~m}$ inside the wall. This condition is used to calculate the temperature in ghost cells near walls according to

$$
\begin{aligned}
& \frac{1}{2}\left(T_{g}+T_{I}\right)=\frac{\left(T_{I}+\phi T_{w}\right)}{(1+\phi)}, T_{w}=300 \mathrm{~K} \\
& \phi=\frac{k_{s} \Delta n}{k_{f} d_{p}}
\end{aligned},
$$

where $k_{s}$ is the thermal conductivity of copper, $k_{f}$ is the thermal conductivity of the fluid at the wall, and $\Delta n$ is the distance from the center of a cell adjacent to the wall to the wall itself. The inflow boundary condition for the hydrogen jet fixes the stagnation pressure and temperature to values of $216675 \mathrm{~Pa}$ and $314 \mathrm{~K}$, respectively.

The LES/RANS simulations were run for a minimum of 15 flow-through times, with one flow-through time being that required for a particle at the nominal free-stream velocity of $1781 \mathrm{~m} / \mathrm{s}$ to traverse the $0.4 \mathrm{~m}$ extent of the combustor. Statistics were taken for the last 10 flow through times. To compare with experimental probe data, the flow properties are averaged in time as well as over a defined region in the spanwise (Z) direction. In cases where periodic boundary conditions are applied in the $\mathrm{Z}$ direction, the averaging region is the entire spanwise expanse of the combustor $(\mathrm{Z}=+/-2.55 \mathrm{~cm})$. In cases where sidewall boundary layers are resolved, the averaging region is over $\mathrm{Z}=+/-1.3 \mathrm{~cm}$ to eliminate flow-property variations within these boundary layers from affecting the averages.

\section{Results}

Table 2 summarizes the different types of simulations performed. LES/RANS calculations involving both inert-gas mixing and combustion were performed using PPM on the smaller periodic domain. LES/RANS calculations with LD-PPM were performed on the larger periodic domain. RANS calculations using PPM and LES/RANS calculations using PPM and LD-PPM were performed on the 3D domain.

Table 2:

\begin{tabular}{|l|l|l|l|l|}
\hline case & thermodynamic model & computational domain & turbulence model & inviscid-flux discretization \\
\hline 1 & inert-gas mixing & periodic & LES/RANS & PPM \\
\hline 2 & 7-species $\mathrm{H}_{2}$ oxidation & periodic & LES/RANS & PPM \\
\hline 3 & 7-species $\mathrm{H}_{2}$ oxidation & periodic (larger grid) & LES/RANS & LD-PPM \\
\hline 4 & 7-species $\mathrm{H}_{2}$ oxidation & 3D & RANS & PPM \\
\hline 5 & 7-species $\mathrm{H}_{2}$ oxidation & 3D & LES/RANS & PPM \\
\hline 6 & 7-species $\mathrm{H}_{2}$ oxidation & 3D & LES/RANS & LD-PPM \\
\hline
\end{tabular}

\section{A. Inert-gas mixing - flow features and comparisons with experimental data}

Figure 2 presents $\mathrm{X}-\mathrm{Y}$ centerplane snapshots of temperature, water mass fraction, and transverse-velocity magnitude contours for the inert-gas mixing case (Table 1) run with the LES/RANS model on the spanwise-periodic domain. The contour ranges for temperature and water mass fraction are the same as for the combusting cases discussed later for ease of visual comparison. The resolved eddies in the incoming boundary layer help to initiate the formation of Kelvin-Helmholz type structures in the inert gas / hydrogen mixing layer. These rapidly grow and then break down in a three-dimensional fashion further downstream. The PPM appears to capture the larger eddy structures (those of the order of the shear layer thickness) reasonably well, but eddies with sizes nearer to the grid scale are not resolved. This is a consequence of the monotonicity-preserving steps in the algorithm, which act to damp local extrema in the solution. Stagnation temperature and Pitot pressure distributions at locations near the entrance to the combustor $(X=0.0 \mathrm{~m})$ and its exit $(X=0.354 \mathrm{~m})$ are shown in Figures 3 and 4 . Predictions at the combustor entrance are actually for the vitiated-air condition (Table 1), as data is unavailable at this location for the inert-gas mixing conditions. Good agreement with experimental distributions is indicated at the entrance location near the lower wall. This is not surprising, as the inflow boundary layer in the computation is targeted to match the 
thickness of the boundary layer measured at this location. Significant discrepancies between computation and experiment are present in the upper wall boundary layer. It is likely that the wind-tunnel nozzle in the experiment is contoured on its upper surface, but in the absence of detailed geometric information, we have simply assumed a symmetric channel inflow. The predictions of Pitot pressure at the combustor exit (Figure 4) are in good agreement with the experiment, while the predictions of stagnation temperature show a systematic deviation from the measured free-stream values. Profiles of nitrogen, water, and hydrogen mole fraction are compared with experimental gassampling measurements in Figure 5. Good agreement is observed, indicating that larger eddies account for the bulk of the mixing process and are adequately resolved and sustained by the PPM.

\section{B. Vitiated-air mixing and combustion - flow features}

Snapshots of temperature, water mass fraction, and hydroxyl $(\mathrm{OH})$ mass fraction at the $\mathrm{X}-\mathrm{Y}$ centerplane of the combustor are shown in Figures 6-8 for Cases 2-6 in Table 2. The RANS solution obtained on the 3D domain (bottom figure in each set) shows a lifted flame, stabilized $\sim 10 \mathrm{~cm}$ downstream of the hydrogen injection position. A shock wave emanates from the flame stabilization location. (Figure 6). This results from the volumetric expansion of the shear layer due to heat release. The $\mathrm{OH}$ radical contours (Figure 8) provide a marker for the flame-front location. The flame stabilization position is furthest downstream $(\sim 22 \mathrm{~cm})$ for the LES/RANS simulation performed using PPM on the periodic domain. Here, turbulent eddies clearly increase in size downstream of the stabilization position and are large enough to deform the reaction front, straining the flame almost to the point of local extinction. Large-scale entrainment of reactants into the reaction zone leads to the formation of pockets of strongly burning fluid, characterized by temperatures in excess of $2500 \mathrm{~K}$ and high water concentrations, intermixed with pockets of cooler fluid. The resolved eddies downstream of the stabilization point are large enough $(2$ to $3 \mathrm{~cm})$ to raise the possibility of an unphysical correlation in the periodic direction, as the extent of the computational domain in this direction is the combustor width of $5.1 \mathrm{~cm}$. As such, these results may be somewhat questionable.

A narrower flame structure, characterized by smaller eddies near the reaction zone, is obtained on the larger periodic domain when the LD-PPM scheme is used. The flame stabilization position moves slightly forward. An induction length of about $5 \mathrm{~cm}$, characterized by the intermittent formation of pockets with high $\mathrm{OH}$ concentration but not substantial heat release, is noted in animations of the flame development. Relative to the PPM results, the LD-PPM scheme appears to promote mixing at smaller scales, leading to more complete combustion and a more connected reaction front.

The sidewall and top boundary layers in the 3D domain range from 1 to $1.5 \mathrm{~cm}$ in thickness in the combustor section (see Figure 9). These provide a displacement effect that acts to compress the flow further. The flame anchoring position moves further upstream for the LES/RANS simulations performed on this domain, to $\sim 18 \mathrm{~cm}$ for the PPM solution and $\sim 16 \mathrm{~cm}$ for the LD-PPM solution. The locations of peak heat release are confined to a narrow band emanating from the stabilization position, and the larger eddies noted in the PPM solution on the periodic domain are not evident in this snapshot. The LD-PPM solutions show evidence of the formation of smaller-scale turbulent eddies superimposed on a larger-scale structure that is also captured by the baseline PPM. These lessenergetic structures do not interact as strongly with the flame front and induce reactant mixing at smaller scales.

Three-dimensional snapshots of temperature at different cross-stream planes in Figure 9 for the LD-PPM solution illustrate the blockage effects of the sidewall boundary layers and also the large degree of variation in the reaction zone structure across the lateral extent of the combustor. Longitudinal vortical structures with sizes of the order of the shear layer thickness deform the flame front significantly in the cross-stream direction, though smallersized structures are also captured. The vertical extent of the reaction zone increases within the sidewall boundary layers, as shown in the time-averaged exit-plane temperature contours included as an inset figure. This effect is likely a result of counter-rotating corner vortices that act to force hot reaction products from the reaction zone toward the wall and into the corner. Average temperatures in the reaction zone are $\sim 1900 \mathrm{~K}-$ substantially less than the peak values of greater than $2500 \mathrm{~K}$ shown in the instantaneous snapshots. This effect is due to large-eddy interactions within the reactant streams which locally strain the flame, reducing the effective reaction rate, and also cool it through engulfment of colder pockets of fluid.

\section{Vitiated-air mixing and combustion - comparisons with experimental data}

Figure 10 presents stagnation temperature profiles at the combustor entrance and exit for the reactive cases. The best agreement with experimental data is obtained from the RANS solution on the 3D domain, which correctly predicts the shear layer thickness, the location of the stagnation temperature peak, and the peak value itself. The PPM solution performed on the spanwise periodic domain predicts the location of the peak reasonably well but the stagnation temperature in the reaction zone is well under-predicted and the thickness of the layer is over-predicted. 
These trends indicate an over-prediction of the rate of reactant mixing downstream of the flame stabilization position. The LD-PPM solution on the expanded periodic domain shows some improvement in the predictions of the peak stagnation temperature and the shear layer width. The LES/RANS solutions performed on the 3D domain also provide better predictions of the peak stagnation temperature and the shear layer thickness, but the location of the peak is shifted further away from the wall. This effect may also be due to the corner vortices mentioned earlier, as these force fluid within the sidewall boundary layers downward into the corner, then laterally toward the centerline, and finally upward into the middle of the combustor. The peak stagnation temperatures as predicted by the LD-PPM LES/RANS models are closer to the experimental results than those of the baseline PPM, an effect probably indicative of an increased level of reactant mixing at smaller scales.

Pitot pressure profiles in Figure 11 show similar trends. The shear layer appears to be further displaced from the lower wall for the LES/RANS solutions obtained on the 3D domain, and again, the best agreement with experimental data is provided by the RANS model. Traces of shock waves traversing the data plane are noted in the profiles.

Mole fraction profiles at $\mathrm{X}=35.4 \mathrm{~cm}$ are shown in Figure 12. The peak in water production is best captured by the RANS model, though its location is shifted toward the wall in comparison with the experimental data. The LES/RANS PPM solution on the periodic domain shows an over-prediction of the shear layer thickness and an under-prediction of the amount of water production. LES/RANS solutions obtained on the 3D domain show some improvement in the prediction of the shear layer thickness but the entire reaction zone is displaced further away from the wall. The LD-PPM provides some improvement in the peak value of water mole fraction, relative to the LES/RANS solutions obtained using PPM.

Static pressure distributions along the lower wall of the combustor are shown in Figure 13 for the inert-gas and vitiated-air cases. It is clear from the comparisons that there are significant discrepancies in the predictions of the initial stages of hydrogen-jet expansion into the air stream. Specifically, there appears to be an expansion wave in the experiment that interacts with the lower wall just downstream of the hydrogen slot position. This could arise from an incomplete cancellation of waves in the actual wind-tunnel geometry, the shape of which is unknown. All calculations predict a rapid increase in pressure near their respective flame-stabilization locations, due to shock waves that form as the shear layer expands after igniting. After this point, the pressures decrease, reaching values comparable to those in the experiment near the end of the combustor. There is no evidence of the formation of shock waves in the experimental distributions, which show a gradual increase in pressure after ignition. This discrepancy with the measurements suggests that the assumptions made in idealizing the wind-tunnel flowfield and the hydrogen jet nozzle may not be adequate.

\section{Vitiated-air mixing and combustion - turbulence / chemistry interactions}

Scatter plots of reactive scalars versus mixture fraction can be used to assess the degree to which resolved turbulent eddies influence the flame behavior. The mixture fraction definition is based on the use of the hydrogen element fraction:

$$
f=\frac{e_{H}-e_{H, 1}}{e_{H, 2}-e_{H, 1}},
$$

with the hydrogen element fraction defined in terms of the species mass fractions as

$$
e_{\mathrm{H}}=Y_{\mathrm{H}_{2}}+Y_{\mathrm{H}_{2} \mathrm{O}} / 9+Y_{\mathrm{OH}} / 17+Y_{\mathrm{H}},
$$

and the subscripts 1 and 2 representing the hydrogen and vitiated-air streams, respectively. The stoichiometric value of the mixture fraction $f_{\mathrm{st}}$ is found by considering combustion of hydrogen at the experimental fuel / vitiatedair ratio of 0.0143 according to the one-step, irreversible reaction

$$
\mathrm{H}_{2}+\frac{1}{2} \mathrm{O}_{2} \Rightarrow \mathrm{H}_{2} \mathrm{O} \text {. }
$$

The stoichiometric mixture fraction is a sensitive function of the fraction of unburned hydrogen assumed to be present after combustion, with values ranging from 0.014 for $0 \%$ unburned hydrogen to .040 for $5 \%$ unburned hydrogen. The data used in the scatter plots was sampled from the PPM solution on the 3D domain at three planes within the combustor - one upstream of the ignition location, one just downstream of this location, and one near the measurement location of $X=35.4 \mathrm{~cm}$. Figure 14 plots major-species mass fractions and temperature versus mixture fraction at the plane upstream of the ignition location. The expected linear variation of species concentration with mixture fraction is recovered in this region. Downstream of the ignition point (Figure 15) the scatter plots reveal a transition between an unburned flamelet structure and a burning flamelet structure. The significant levels of scatter indicate that transient ignition events are present in this region and that the lifted flame allows some oxygen and 
water vapor to mix with the hydrogen stream without passing through the reaction zone. Near the combustor exit (Figure 16), peaks in temperature and the minor species $\mathrm{OH}$ and $\mathrm{O}$ atom (not shown) are located within the range calculated above for the stoichiometric mixture fraction $(0.014$ to 0.04$)$. If the $\mathrm{OH}$ peak can be identified with the true stoichiometric mixture fraction contour, then the peak temperature values occur toward the fuel-rich side and the peak $\mathrm{O}$ atom values occur toward the fuel-lean side. Peak values of water and $\mathrm{H}$ atom are located at higher (fuel rich) values of the mixture fraction. Flame-lift effects are indicated also at this station, as unburned oxygen and hydrogen is still present beneath the flame front. The scatter in the composition variables about mixture-fraction conditioned averages indicates the effect of turbulent eddy interactions in locally straining the flame. These results provide evidence that a strained flamelet model for turbulent combustion is valid in this region of the flame.

\section{Conclusions}

Simulations of the well-known Burrows and Kurkov reacting wall-jet experiment using RANS and LES/RANS methods have been described in this paper. Calculations have been performed on an idealized 2D geometry, in which sidewall effects are neglected, and a fully 3D geometry, in which top and side-wall boundary layers are resolved. The LES/RANS model provides good predictions of non-reactive mixing of the hydrogen jet and the vitiated-air stream. Simulations including chemical reactions predict a lifted flame, stabilized from 16 to $22 \mathrm{~mm}$ downstream of the injection location.. The flame anchoring position moves toward the fuel injection location for calculations performed on the 3D domain, and the reaction zone structure is influenced by the formation of counterrotating vortex pairs in the side-wall / lower-wall junctures. In all cases, the ignition event causes significant changes in the structure of the shear layer. Combustion-induced volumetric expansion leads to an enhanced growth rate of the shear layer and the formation of large eddies that act to stretch the flame and to force large pockets of colder reactant fluid toward the flame front. The breakdown of these larger structures into smaller-scale ones is enhanced by the use of lower-dissipation version of the baseline piecewise-parabolic advection scheme (termed LDPPM). The LD-PPM provides some improvement in the prediction of the time-averaged reaction-zone structure, yielding higher peak values of stagnation temperature and water mole fraction that imply more complete mixing and combustion at smaller scales. The reaction zone obtained on the 3D domain is shifted further away from the wall than indicated in the experimental data. This effect is due to the lifting action of the counter-rotating vortex pairs mentioned earlier and may imply that the LES/RANS model over-predicts the growth rate of the sidewall boundary layers. All LES/RANS models under-estimate the peak levels of stagnation temperature and water concentration in the time-averaged reaction zone. This appears to be a consequence of too-rapid mixing of colder reactants at larger turbulence length scales. As shown in many other studies, the baseline RANS model provides predictions that are generally in good agreement with experimental data. Though subgrid models for the filtered chemical production rates have yet to be considered in this work, it is clear that for better agreement with experimental data, the net effect of such models must be to increase the local reaction rate within a mesh cell, thereby increasing the rate of heat release and providing less sensitivity to fluctuating strain rates. The over-mixing effects of the very largest turbulent eddies seem to be mitigated somewhat by the use of the less-dissipative LD-PPM, which better captures the range of length scales that should be resolvable on the grid.

\section{Acknowledgments}

This work is supported by NASA under Cooperative Agreement NNX07AC27A-S01. Computer resources have been provided by the NASA Advanced Supercomputing (NAS) division.

\section{References}

[1] Baurle, R.A. “Modeling of High-Speed Reacting Flows: Established Practices and Future Challenges” AIAA Paper 20040267, Jan. 2004

[2] Edwards, J.R., Choi, J-I., and Boles, J.A. "Hybrid Large-Eddy / Reynolds-Averaged Navier-Stokes Simulation of a Mach-5 Compression Corner Interaction”, AIAA Journal, Vol. 46, No. 4, 2008, pp. 977-991.

[3] Choi, J.-I., Edwards, J.R., and Baurle, R.A. "Compressible Boundary Layer Predictions at High Reynolds Number using LES/RANS Models” AIAA Journal, Vol. 47, No. 9, 2009, pp. 2179-2193.

[4] Boles, J.A., Choi, J.-I., Edwards, J.R., and Baurle, R.A. "Simulations of High-Speed Internal Flows Using LES/RANS Models” AIAA Paper 2009-1324, Jan. 2009

[5] Ghosh, S., Choi, J-I., and Edwards, J.R. "Simulations of Shock / Boundary Layer Interactions with Bleed using Immersed Boundary Methods,” AIAA Paper 2009-1330, Jan. 2009.. 
[6] Genin, F., Chernyavsky, B. and Menon, S., "Large eddy simulation of scramjet combustion using a subgrid mixing/combustion model,” AIAA-2003-7035, Dec., 2003.

[7] Genin, F. and Menon, S. "Simulation of Turbulent Mixing Behind a Strut Injector In Supersonic Flow” AIAA Paper 2009132, Jan. 2009.

[8] Berglund, M. and Fureby, C. "LES of Supersonic Combustion in a Scramjet Engine Model” Proceedings of the Combustion Institute, Vol. 31, No. 2, 2007, pp. 2497-2504.

[9] Waidmann W., Alff, F., Brummund, U., B’ohm, M., Clauss, W., Oschwald, M., Space Technology 15 , 1995) $421-429$.

[10] Oevermann, M. "Numerical Investigation of Turbulent Hydrogen Combustion in a SCRAMJET using Flamelet Modeling" Aerospace Science and Technology, Vol. 4, No. 7, 2000, pp. 463-480.

[11] Berglund, M., Fureby, C. Sabel'nikov, V., and Tegner, J. "On the Influence of Finite-Rate Chemisty in LES of Supersonic Combustion” $32^{\text {nd }}$ International Symposium on Combustion, Montreal, Canada, Paper 1E12, August, 2008.

[12] Peterson, D.M. and Candler, G.V. "Hybrid RANS/LES of a Supersonic Combustor,” AIAA Paper 2008-6923, July, 2008.

[13] Peterson, D.M., Candler, G.V., and Drayna, T.W. "Detached Eddy Simulation of a Generic Scramjet Inlet and Combustor" AIAA Paper 2009-0130, Jan. 2009.

[14] O’Byrne, S., Danehy, P.M., and Cutler, A.D. "Dual-Pump CARS Thermometry and Species Concentration Measurements in a Supersonic Combustor” AIAA Paper 2004-0710, Jan. 2004.

[15] Burrows, M. C.; Kurkov, A. P. "Supersonic Combustion of Hydrogen in a Vitiated Air Stream using Stepped Wall Injection” NASA-TM-X-67840, Jan. 1971.

[16] Burrows, M. C.; Kurkov, A. P., "Analytical and Experimental Study of Supersonic Combustion of Hydrogen in a Vitiated Airstream” NASA-TM-X-2828, Sept., 1973.

[17] Keistler, P.G., Gaffney, R.L., Xiao, X., and Hassan, H.A. “Turbulence Modeling for Scramjet Applications” AIAA Paper 2005-5382, June, 2005.

[18] Engblom, W., Frates, F., and Nelson, C.C. "Progress in Validation of Wind-US for Ramjet / Scramjet Applications” AIAA Paper 2005-1000, Jan, 2005.

[19] Deepu, M., Gokhale, S., and Jayaraj, S. “Numerical Simulation of Supersonic Combustion using Unstructured Point Implicit Finite Volume Method” Journal of the Combustion Society of Japan, Vol. 48, No. 144, 2006, pp. 187-197.

[20] Brinckman, K., Calhoon, W.H., and Dash, S.M. "Scalar Fluctuation Modeling for High-Speed Aeropropulsive Flows," AIAA Journal Vol. 45, No. 5, 2007, pp. 1036-1046.

[21] Ebrahimi, H. B., "CFD Validation for Scramjet Combustor and Nozzle Flows, Part I," AIAA-1993-1840, June, 1993.

[22] Drummond, J.P. and Rogers, R.C. “A Numerical Model for Supersonic Reacting Mixing Layers” Computer Methods in Applied Mechanics and Engineering, Vol. 64, 1987, pp. 39-60.

[23] Eklund, D.R. and Stouffer, S.D. “A Numerical and Experimental Study of a Supersonic Combustor Employing Swept Ramp Fuel Injectors” AIAA Paper 94-2819, June, 1994.

[24] McBride, B.J., Gordon, S., and Reno, M.A. "Coefficients for Calculating Thermodynamic and Transport Properties of Individual Species,” NASA TM-4513, 1993.

[25] Menter, F.R. “Two Equation Eddy Viscosity Turbulence Models for Engineering Applications,” AIAA Journal, Vol. 32, No. 8, 1994, pp. 1598-1605.

[26] Lenormand, E., Sagaut, P., Ta Phuoc, L., and Comte, P., "Subgrid-Scale Models for Large-Eddy Simulations of Compressible, Wall-Bounded Flows,” AIAA Journal, Vol. 38, 2000, pp. 1340-1350.

[27] Boles, J.A., Choi, J.-I., Edwards, J.R., and Baurle, R.A. "Multi-wall Recycling / Rescaling Method for Inflow Turbulence Generation,” AIAA Paper 2010-1099, Jan. 2010.

[28] Colella, P., and Woodward, P. R., “The Piecewise Parabolic Method (PPM) for Gas-Dynamical Simulations,” Journal of Computational Physics, Vol. 54, 1984, pp. 174-201

[29] Edwards, J.R. “A Low-Diffusion Flux-Splitting Scheme for Navier-Stokes Calculations,” Computers and Fluids, Vol. 26, No. 6, 1997, pp. 635-659.

[30] Jameson, A., "Formulation of Kinetic Energy Preserving Conservative Schemes for Gas Dynamics and Direct Numerical Simulation of One-Dimensional Viscous Compressible Flow in a Shock Tube Using Entropy and Kinetic Energy Preserving Schemes” Journal of Scientific Computing, Vol 34, No. 2, 2008, pp. 188-208.

[31] Subbareddy, P.K, and Candler, G.V. "A Fully Discrete, Kinetic Energy Consistent Finite-Volume Scheme for Compressible Flows” Journal of Computational Physics, Vol. 228, No. 5, 2009, pp. 1347-1364.

[32] Ducros, F., Ferrand, V., Nicaud, F., Weber, C., Darracq, D., Gachareiu, C., Poinsot, T. "Large-Eddy Simulation of the Shock / Turbulence Interaction” Journal of Computational Physics, Vol. 152, No. 2., 1999, pp. 517-549.

[33] Star, J.B., Edwards, J.R., Smart, M.K, and Baurle, R.A. "Investigation of Scramjet Flowpath Instability in a Shock Tunnel," AIAA Paper 2006-3040, June, 2006. 


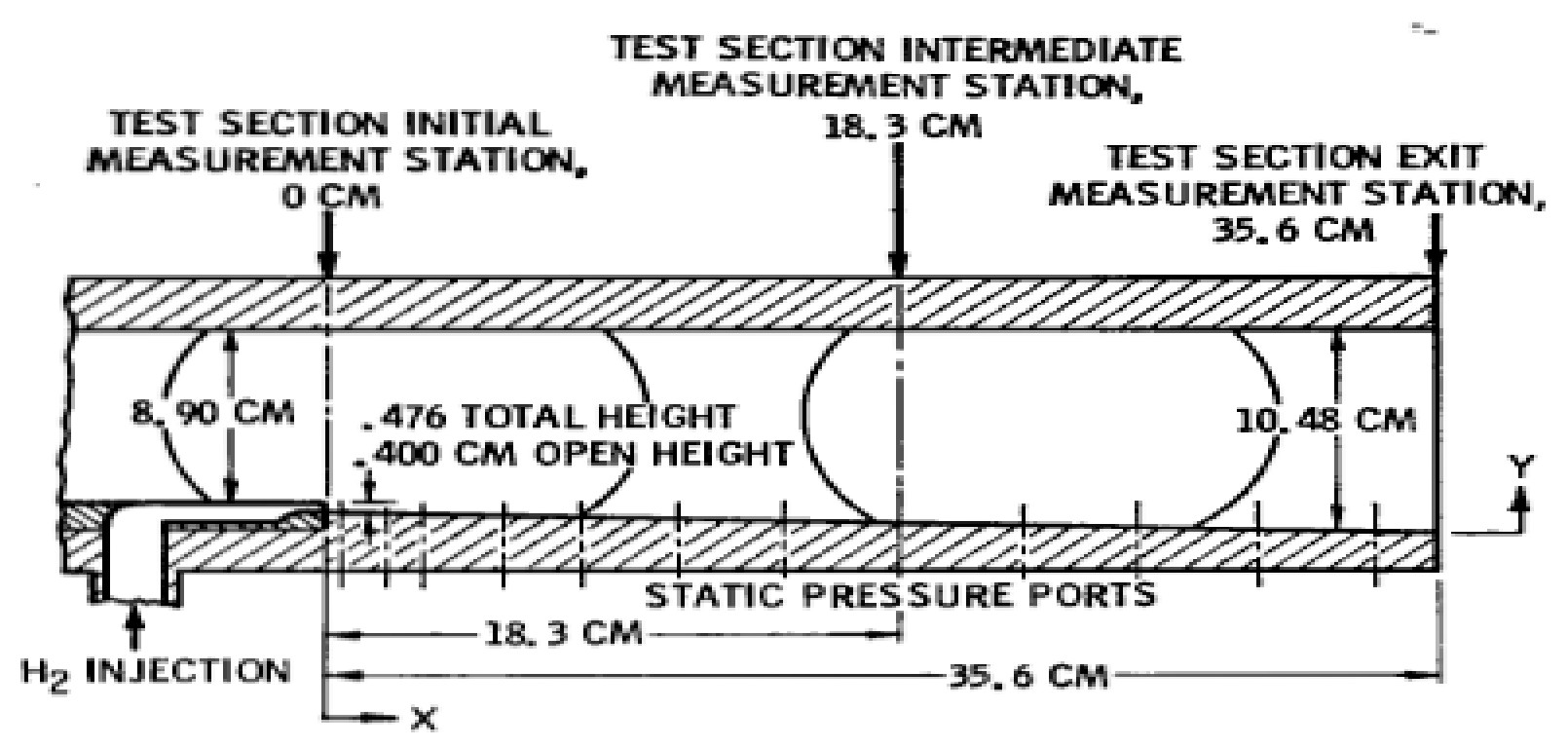

Figure 1: Schematic of Burrows and Kurkov combustor (from Ref [15]) 


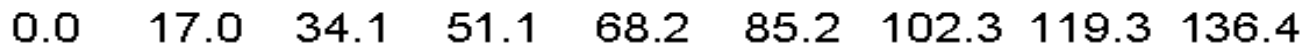

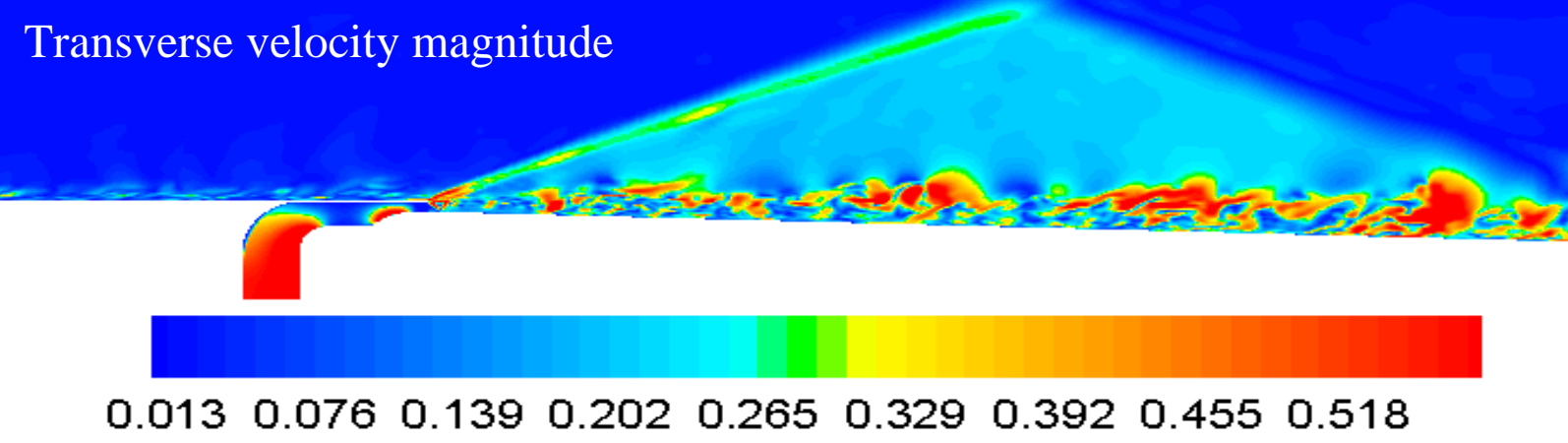

$\mathrm{H}_{2} \mathrm{O}$ mass fraction

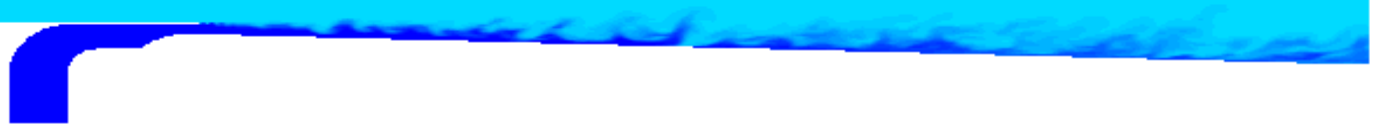

$\begin{array}{lllllllll}266.1 & 520.0 & 773.8 & 1027.7 & 1281.5 & 1535.4 & 1789.2 & 2043.1 & 2296.9\end{array}$

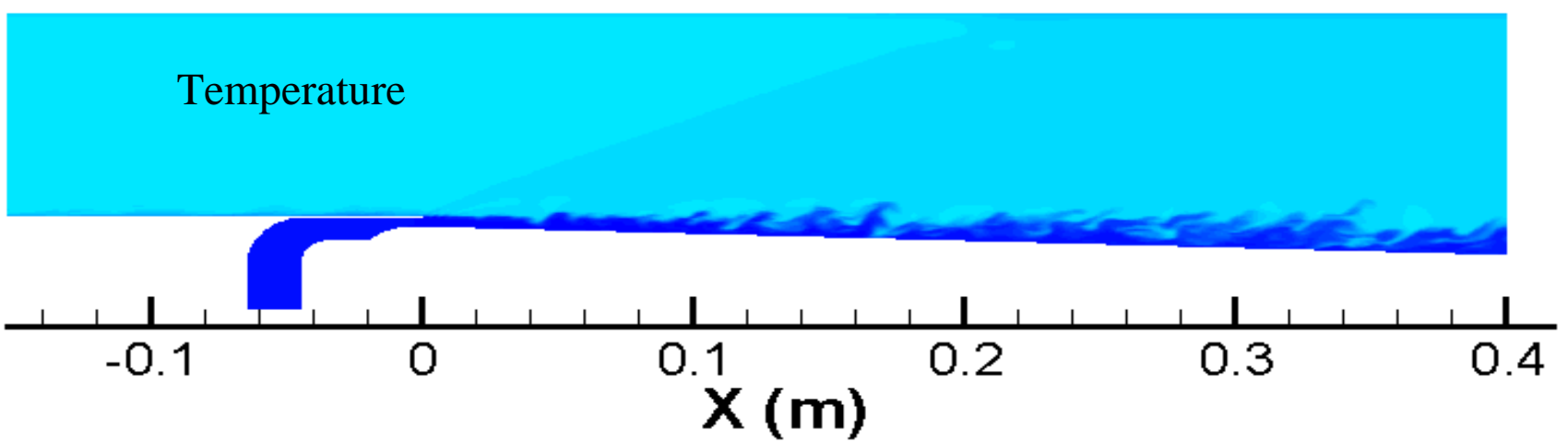

Figure 2: Contours of temperature, water mass fraction, and transverse velocity magnitude (X-Y centerplane, inert gas mixing,) 


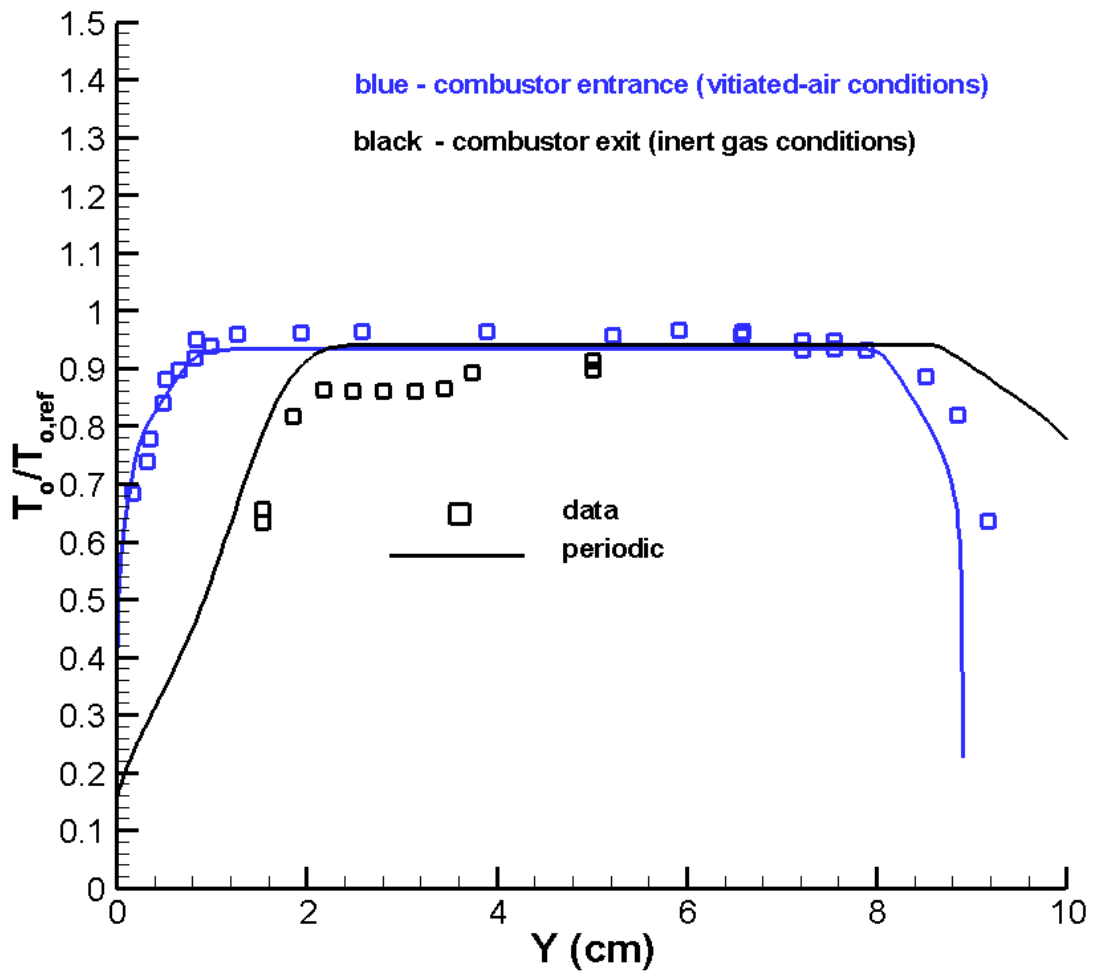

Figure 3: Stagnation temperature profiles (inert-gas mixing)

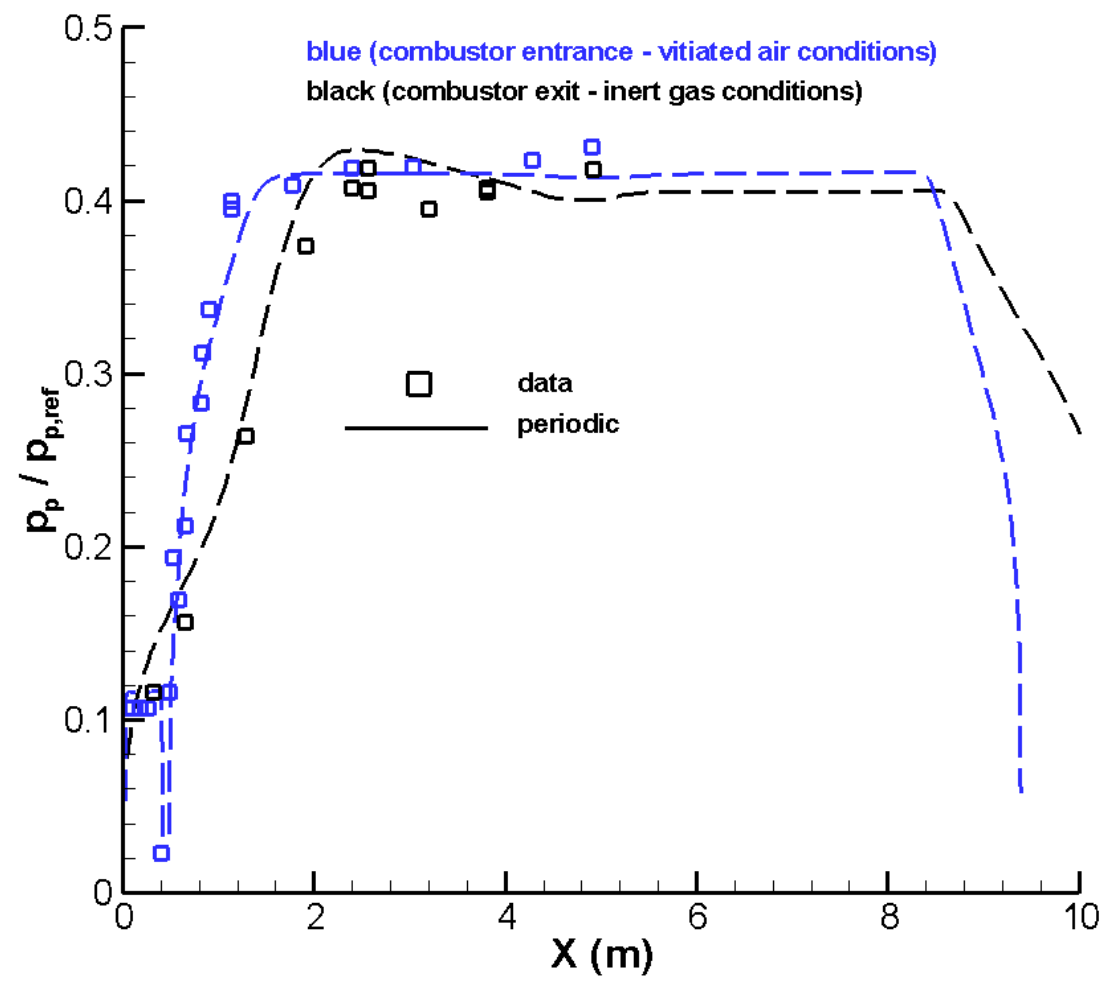

Figure 4: Pitot pressure profiles (inert gas mixing)

American Institute of Aeronautics and Astronautics 


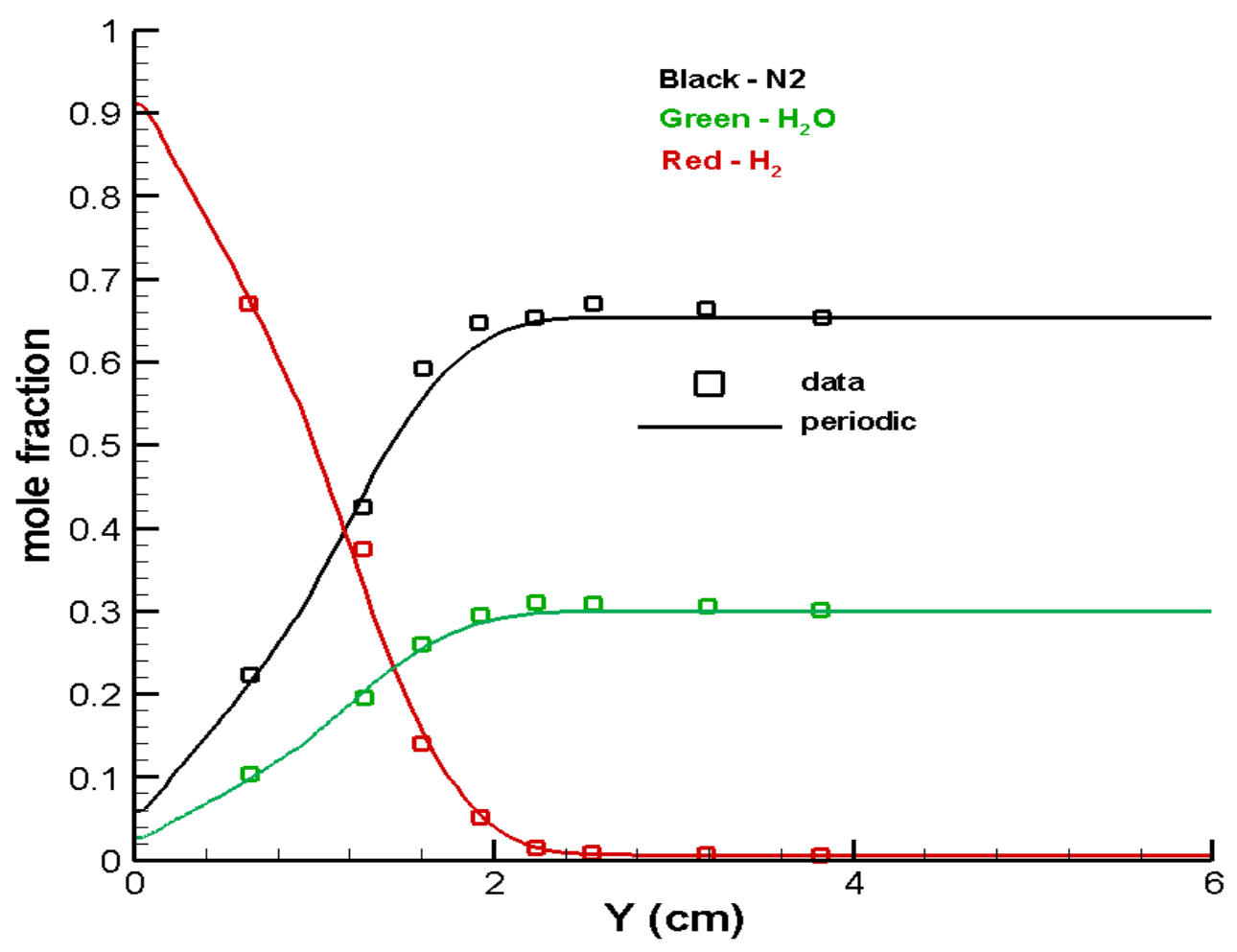

Figure 5: Mole fraction profiles at combustor exit (inert-gas mixing) 

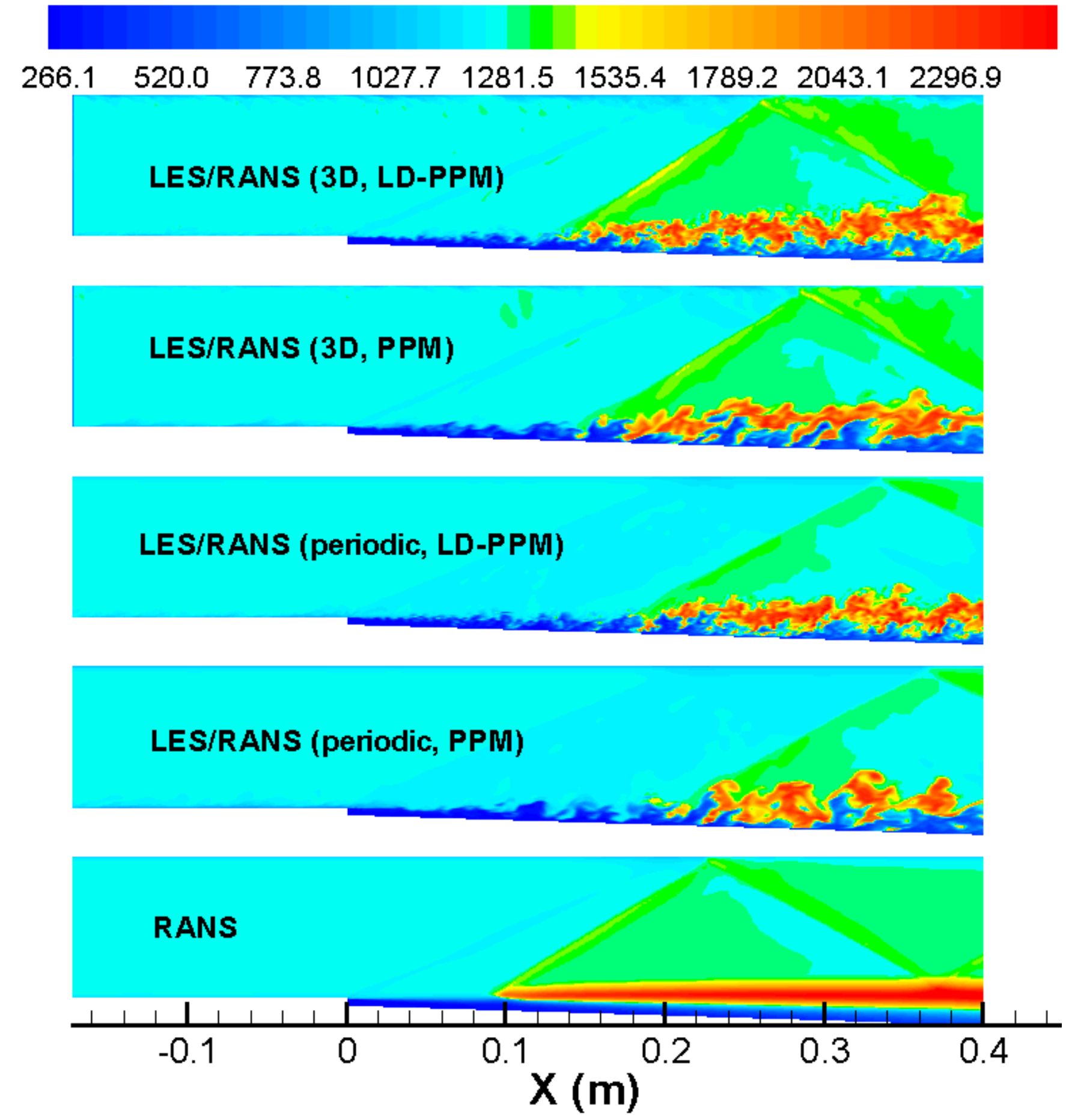

Figure 6: Temperature contours at $\mathrm{X}-\mathrm{Y}$ centerplane (vitiated-air mixing and combustion) 
$\begin{array}{lllllllll}0.013 & 0.076 & 0.139 & 0.202 & 0.265 & 0.329 & 0.392 & 0.455 & 0.518\end{array}$

LES/RANS (3D, LD-PPM)

LES/RANS (3D, PPM)

LES/RANS (periodic, LD-PPM)

LES/RANS (periodic, PPM)

RANS

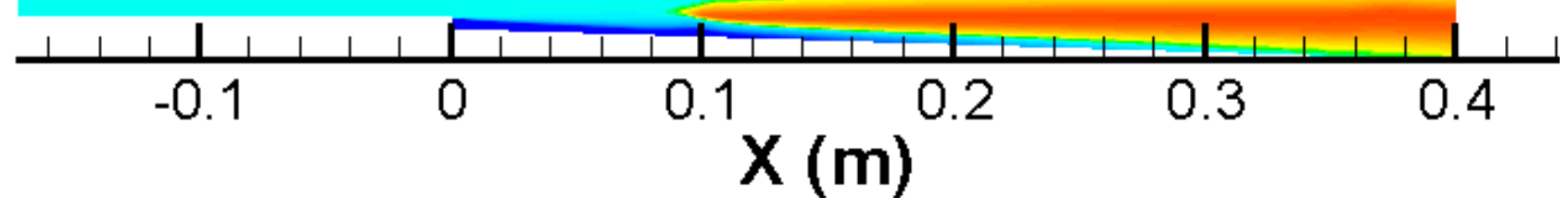

Figure 7: Water mass fraction contours at $\mathrm{X}-\mathrm{Y}$ centerplane (vitiated-air mixing and combustion) 
LES/RANS (3D, LD-PPM)

LES/RANS (3D, PPM)

LES/RANS (periodic, LD-PPM)

LES/RANS (periodic, PPM)
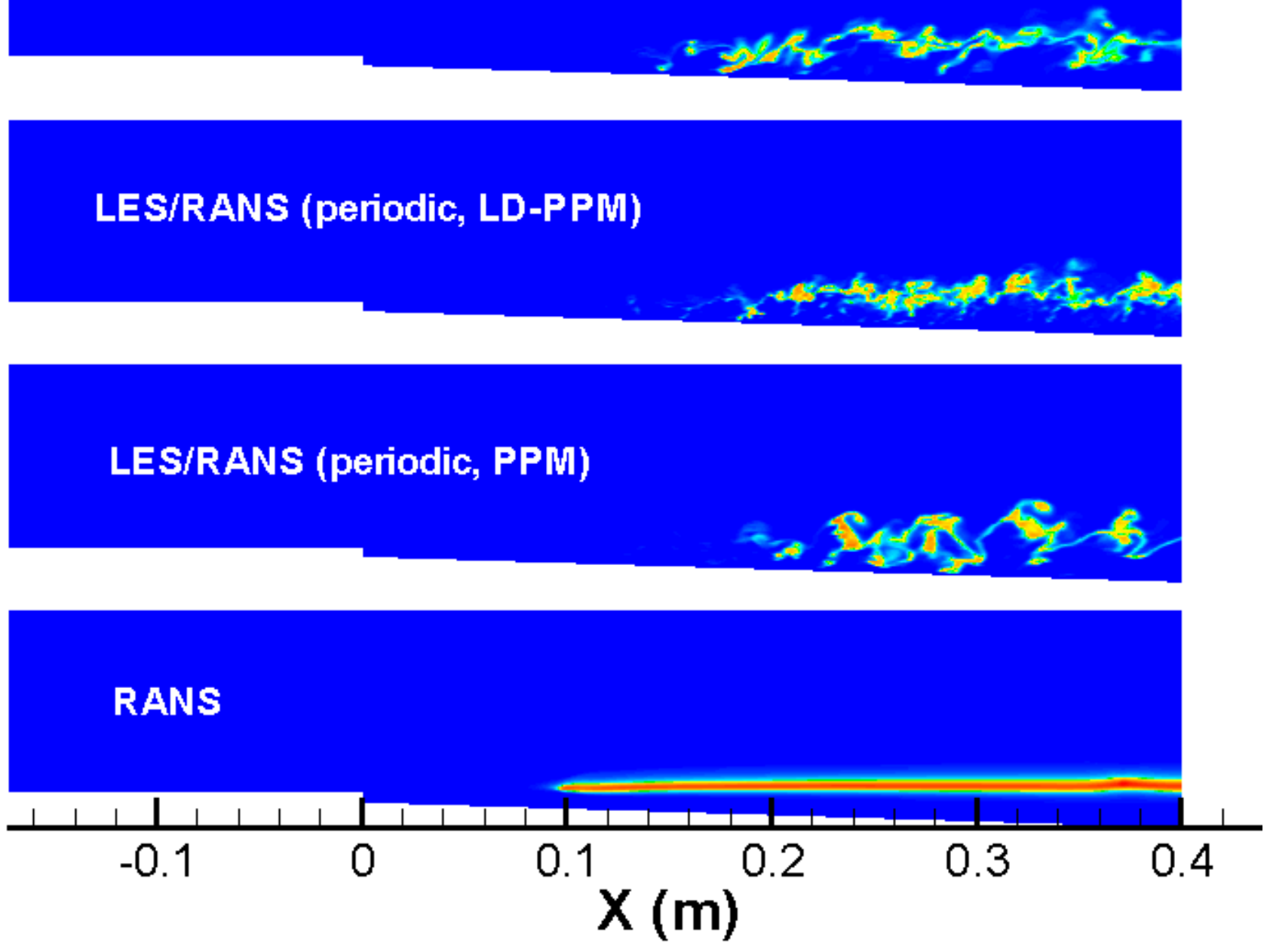

Figure 8: $\mathrm{OH}$ mass fraction contours (vitiated-air mixing and combustion) 


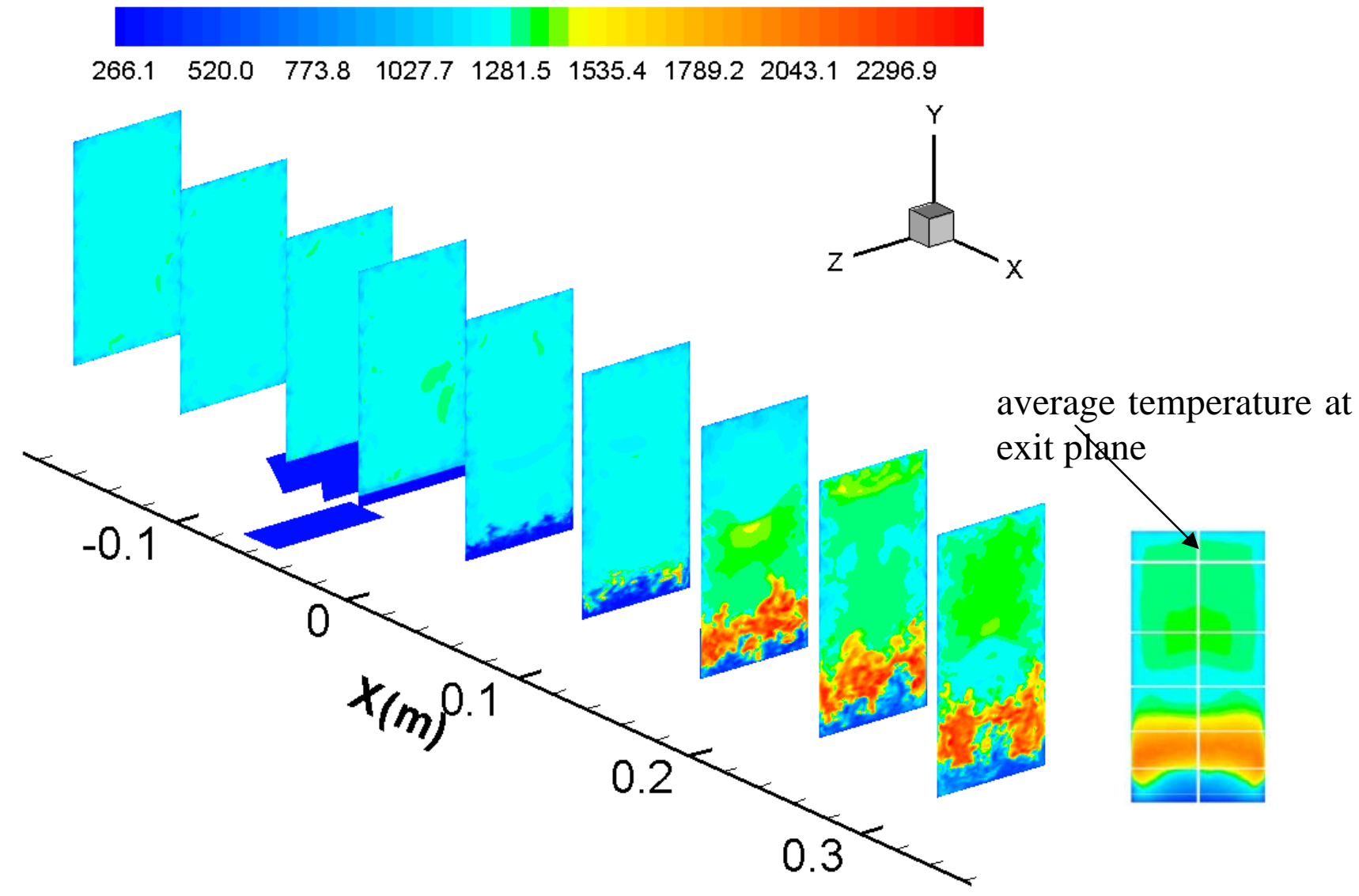

Figure 9: Temperature contours at different cross-stream planes (vitiated-air mixing and combustion)

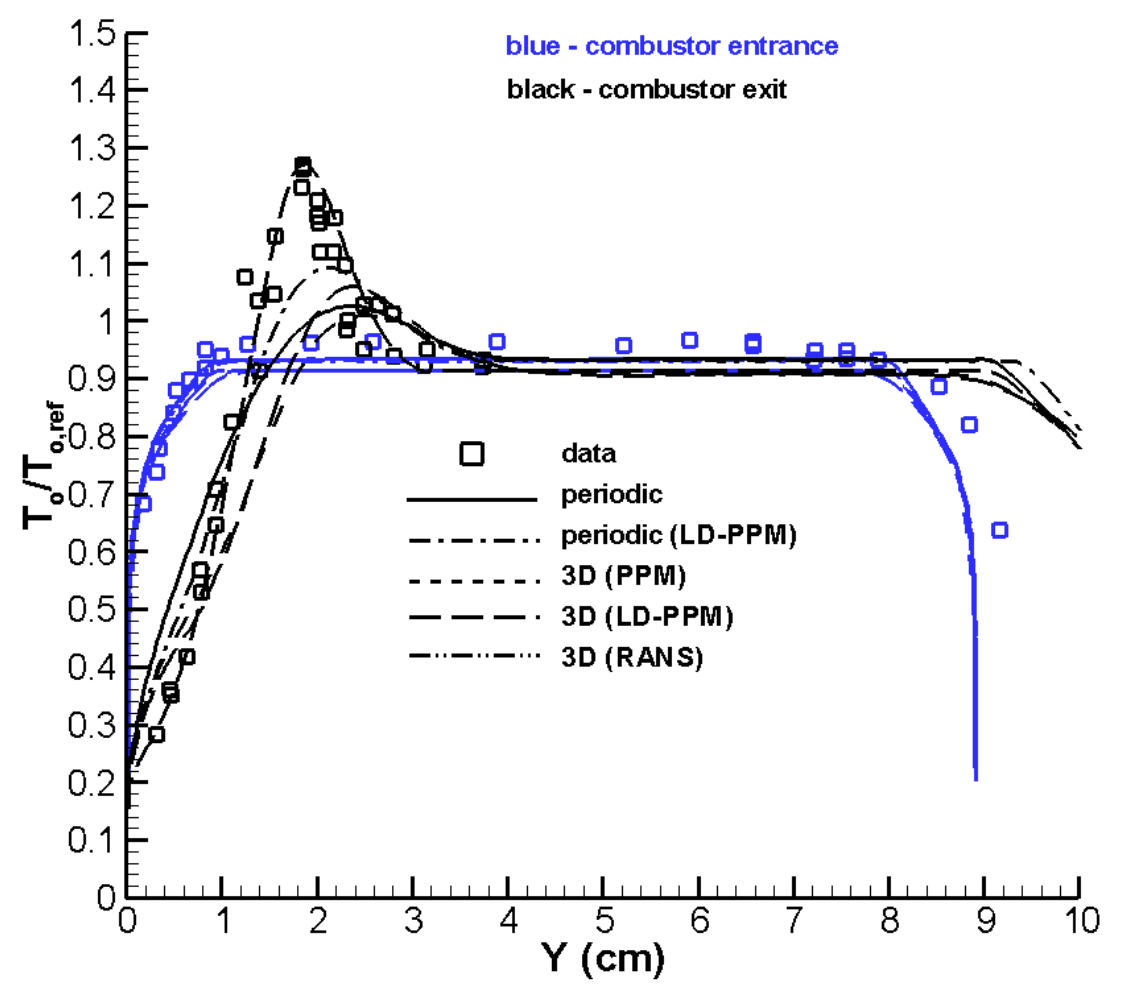

Figure 10: Stagnation temperature profiles (vitiated-air mixing and combustion) 


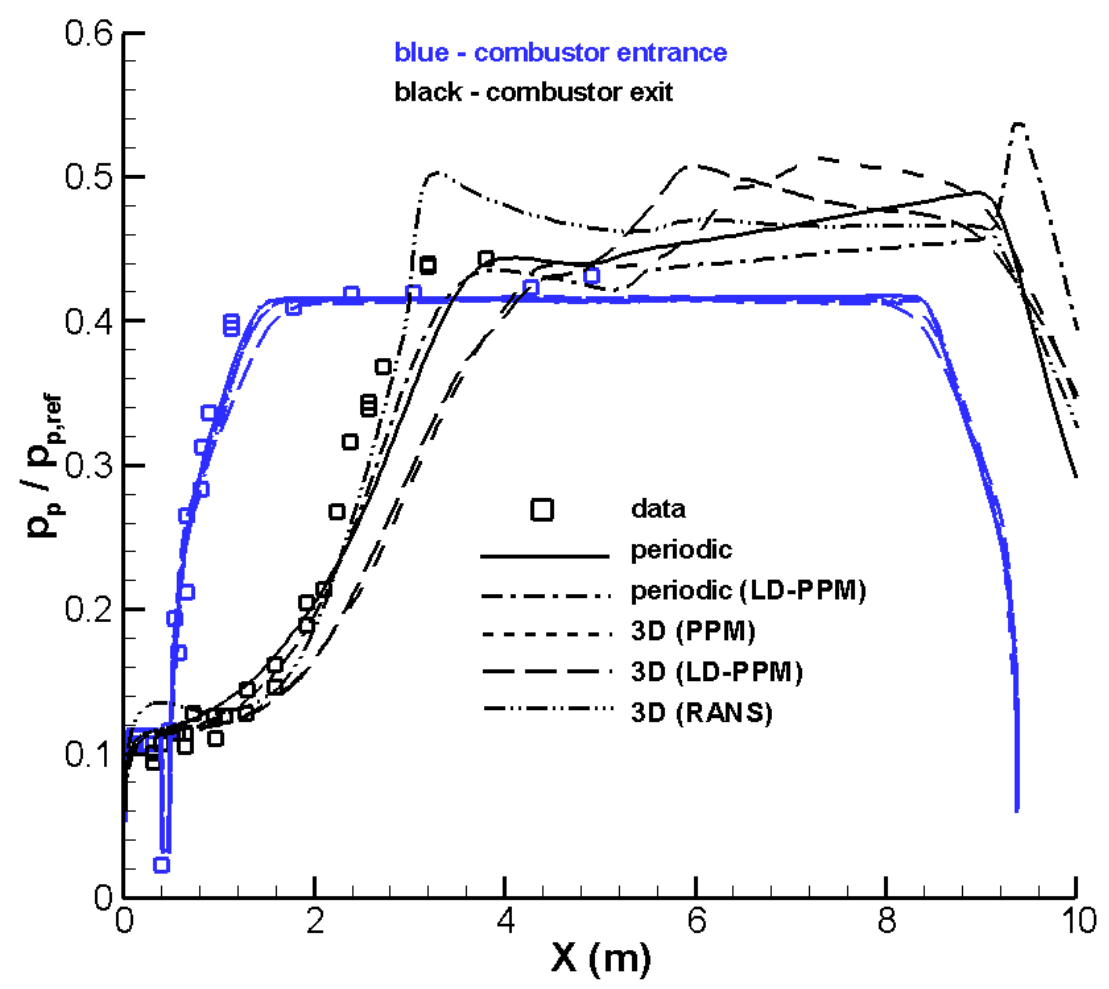

Figure 11: Pitot pressure profies (vitiated-air mixing and combustion)

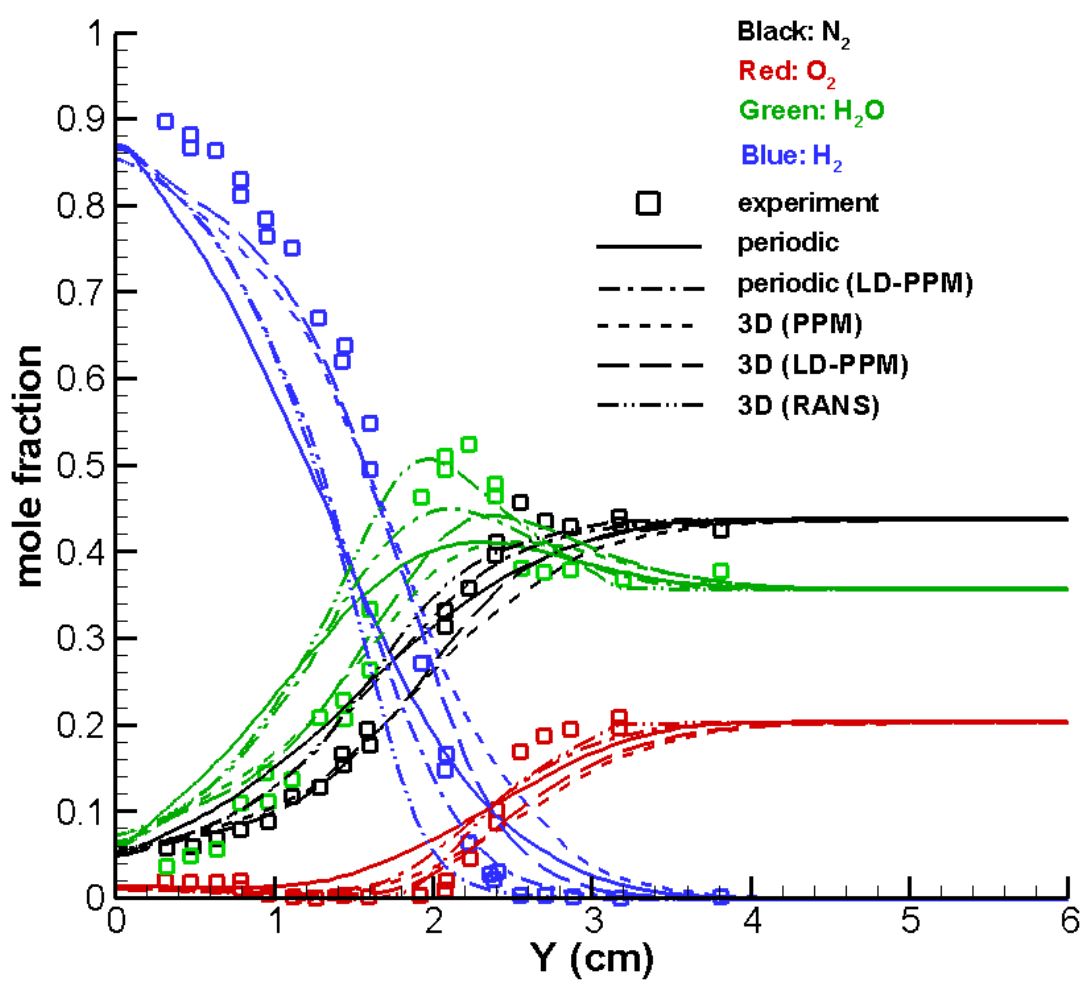

Figure 12: Mole fraction profiles at combustor exit (vitiated-air mixing and combustion)

American Institute of Aeronautics and Astronautics 


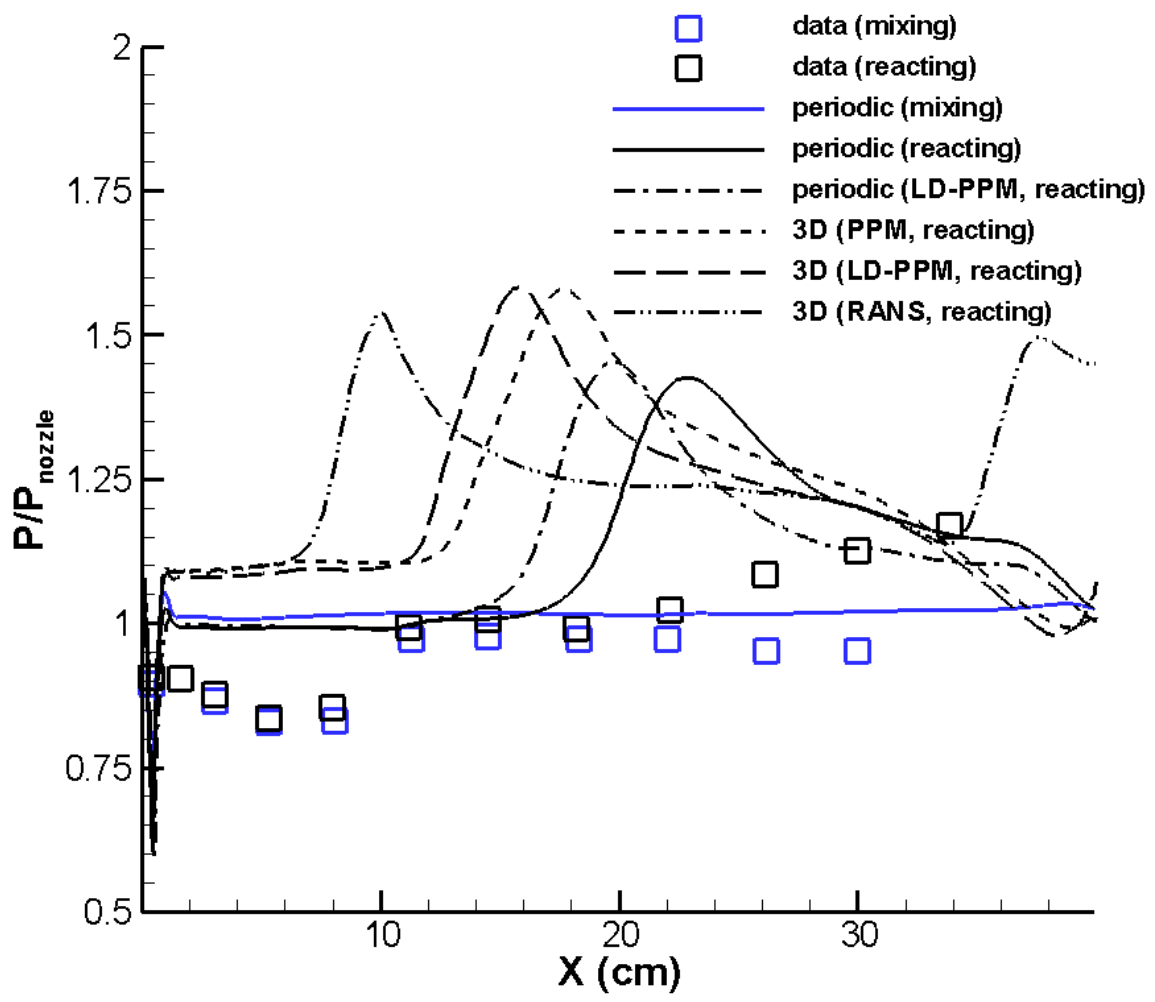

Figure 13: Static pressure distributions along combustor lower wall

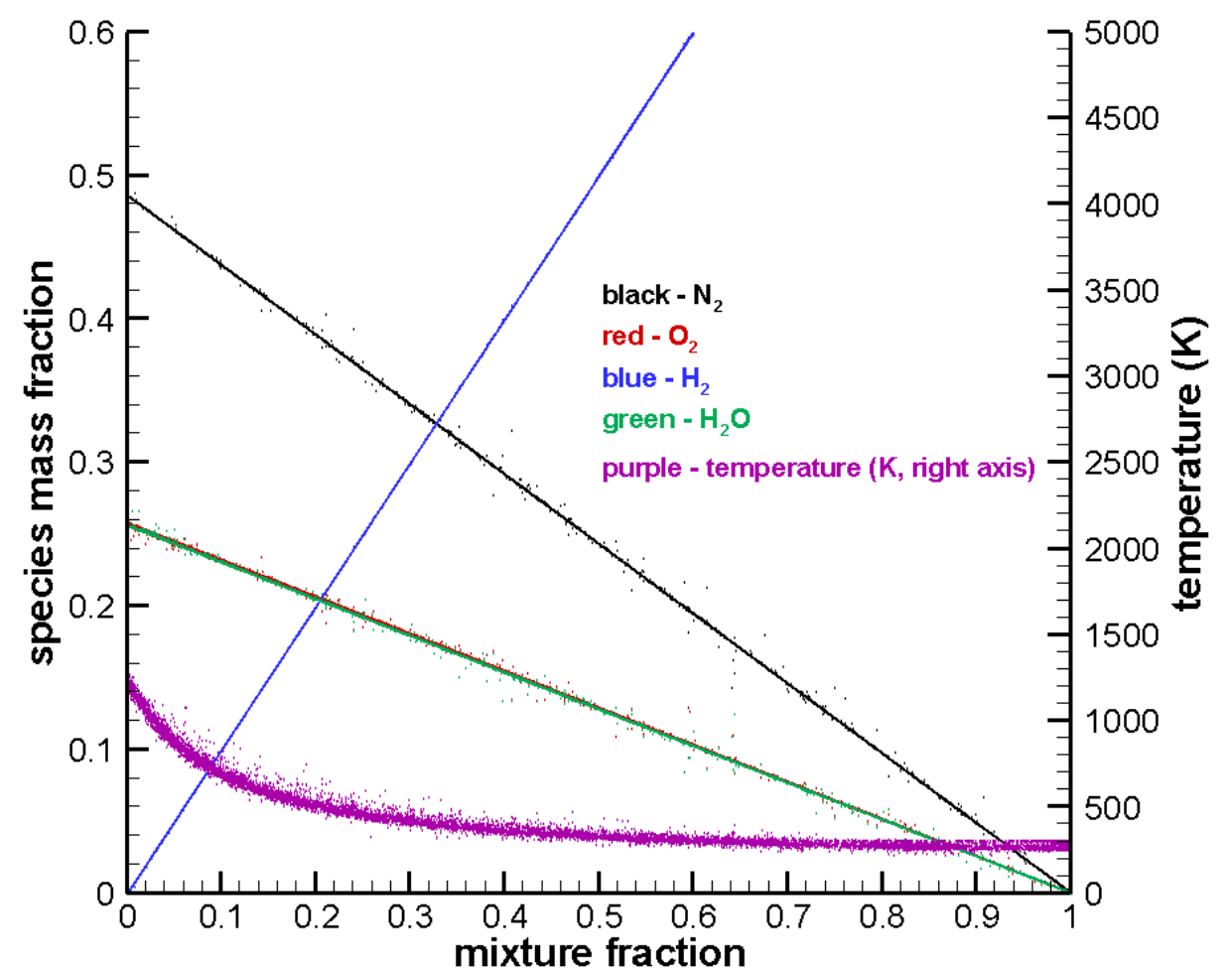

Figure 14: Scatter plots of reactive scalar and temperature versus mixture fraction (location upstream of ignition) 


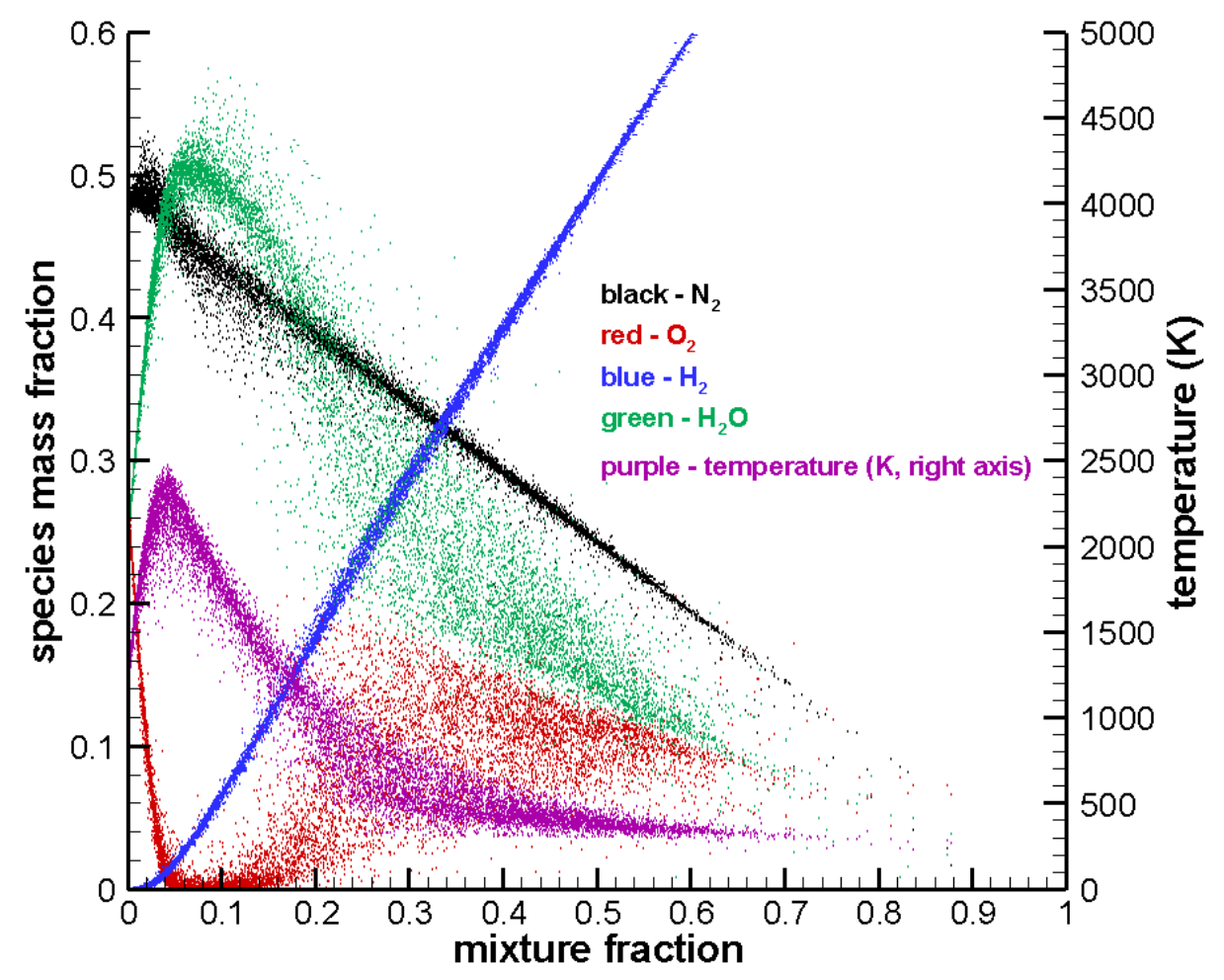

Figure 15: Scatter plots of reactive scalars and temperature versus mixture fraction (location just downstream of ignition)

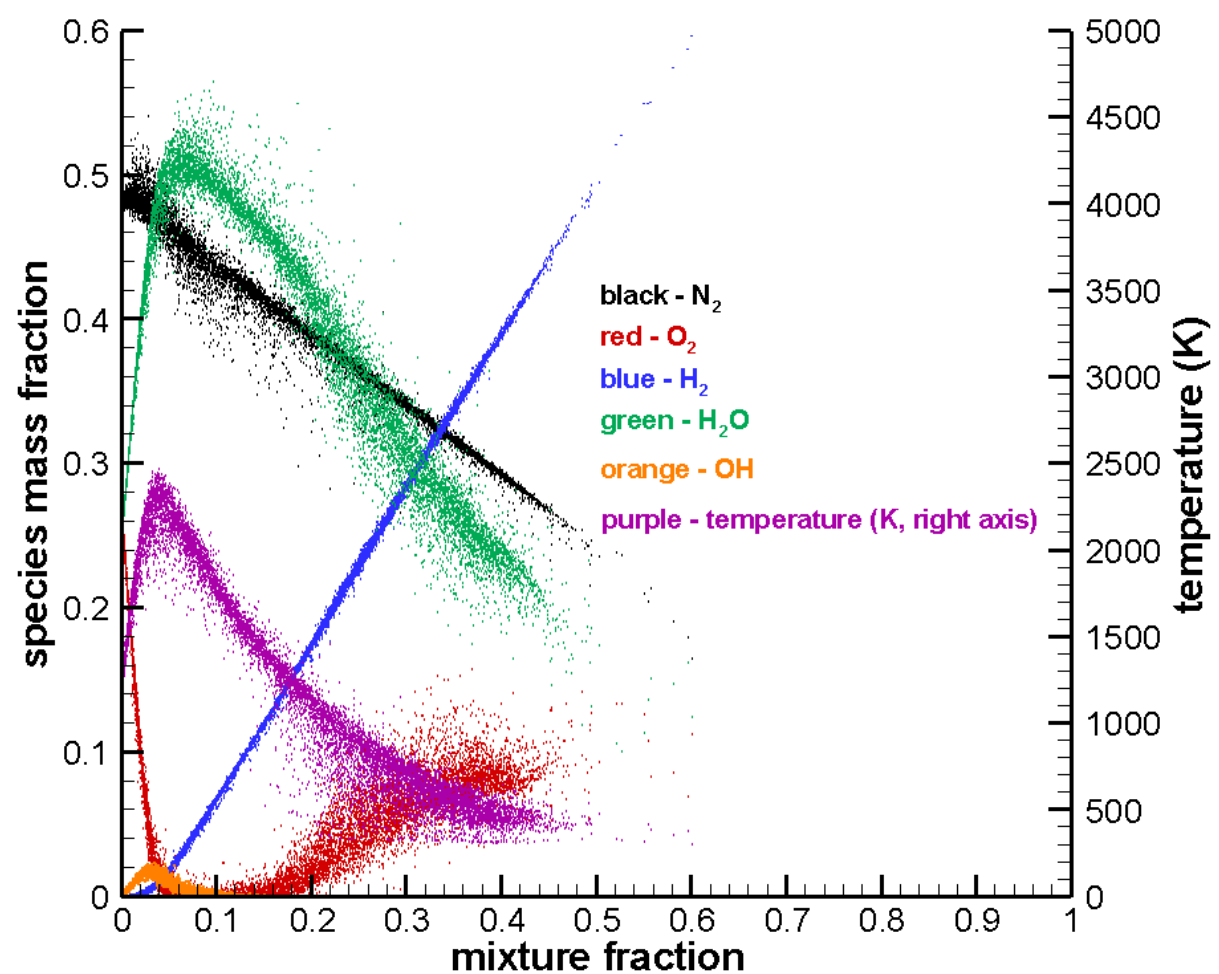

Figure 16: Scatter plots of reactive scalars versus mixture fraction and temperature versus mixture fraction (combustor exit)

American Institute of Aeronautics and Astronautics 